\title{
EVIDENCE OF WORKERS SERVING AS QUEENS \\ IN THE GENUS DIACAMMA
}

(Hymenoptera: Formicidae)

\author{
By MarK W. MoffetT \\ Museum of Comparative Zoology, Harvard University, \\ Cambridge, Massachusetts 02138
}

There is no morphologically distinguishable queen caste known in the ponerine genus Diacamma. Wheeler and Chapman (1922) observed a typical Diacamma worker copulating with a normal male, and it has been assumed that some workers are functioning as reproductives. I report an experiment that supports this view.

Ants in the D. rugosum complex at Sullia in Karnataka State, southern India, live in polydomous colonies; foragers move freely between nests within a colony, which are separated by one to several meters. Each nest is a blind-ended tunnel $10-25 \mathrm{~cm}$ deep containing brood and between about 50-120 workers. When individual nests within a colony were collected and kept in captivity, some workers foraged frequently, while the remainder never left the artificial nest tubes.

In a preliminary experiment conducted during February and March, 1982, the ants taken from one nest were sorted into foraging and non-foraging behavioral types and then further divided into groups of 5-6, with eight groups of foragers (total 45 ants) and four groups of non-foragers (total 21 ants); every group was provided a separate test tube "nest" with stoppered water source and no brood. The foraging ants continued to come and go from their nest tubes, and in none of these groups were any eggs produced over a period of a month. Non-foraging ants continued to stay within their nest tubes and eventually had to be provided food within the tubes. In all four non-foraging groups the test tubes soon held brood, and the five immatures that survived to the pupal stage (three from one tube and two from another) were workers.

This indicates that part of the worker population is fertilized and is serving as queens, as is the case with the African ponerine Ophthalmopone berthoudi (Peeters and Crewe, 1984, 1985), which also lacks winged gynes.

I am grateful to R. Gadagkar and M. Gadgil for aid during my stay in India. 


\section{Literature Cited}

Peeters, C. ANd R. Crewe. 1984. Insemination controls the reproductive division of labor in a ponerine ant. Naturwissenschaften 71: 50-51.

1985. Worker reproduction in the ponerine ant Ophthalmopone berthoudi: an alternative form of eusocial reproduction. Behav. Ecol. Sociobiol. 18: 29-37.

WheEler, W.M. and J.W. Chapman. 1922. The mating of Diacamma. Psyche 29: 203-211. 

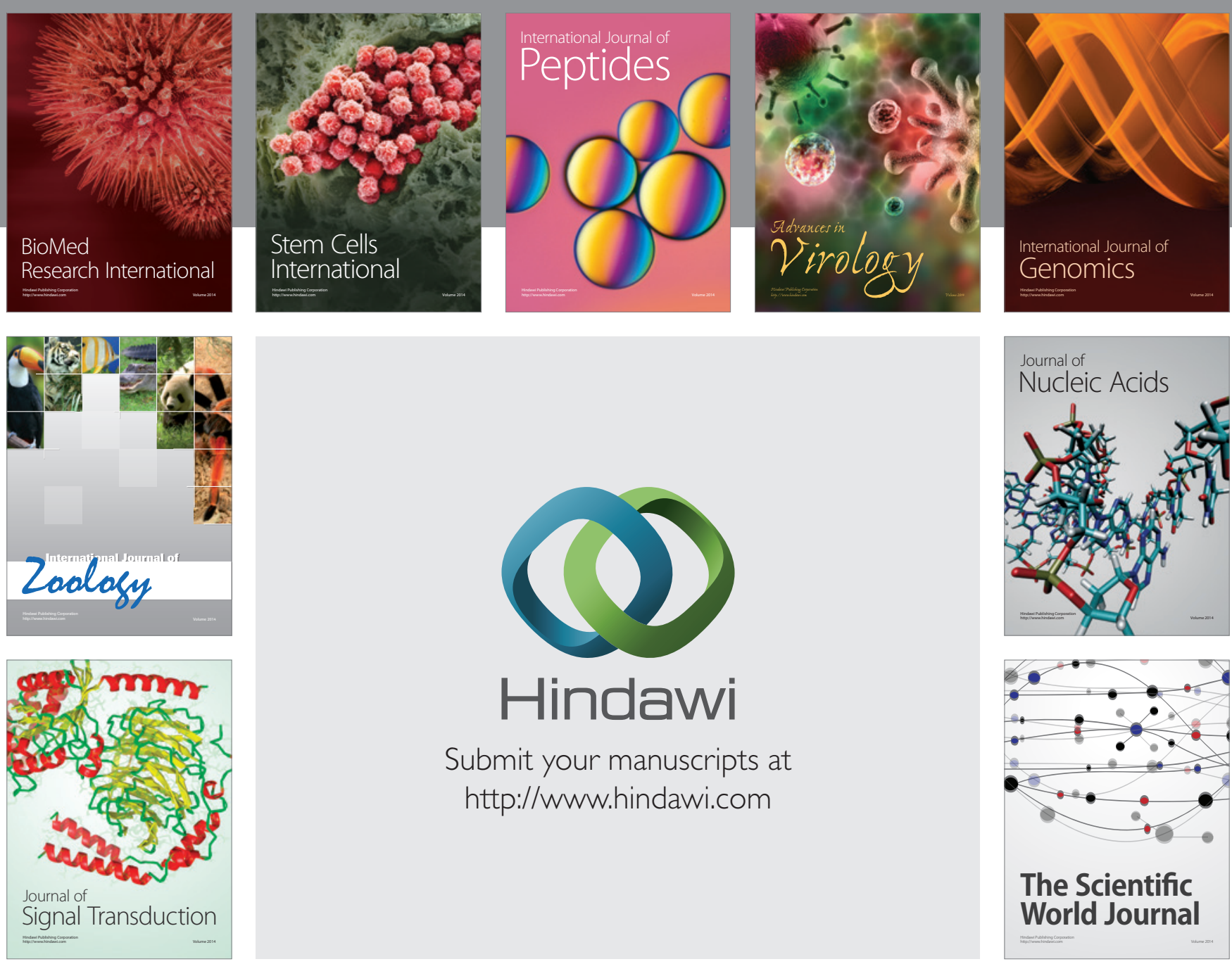

Submit your manuscripts at

http://www.hindawi.com
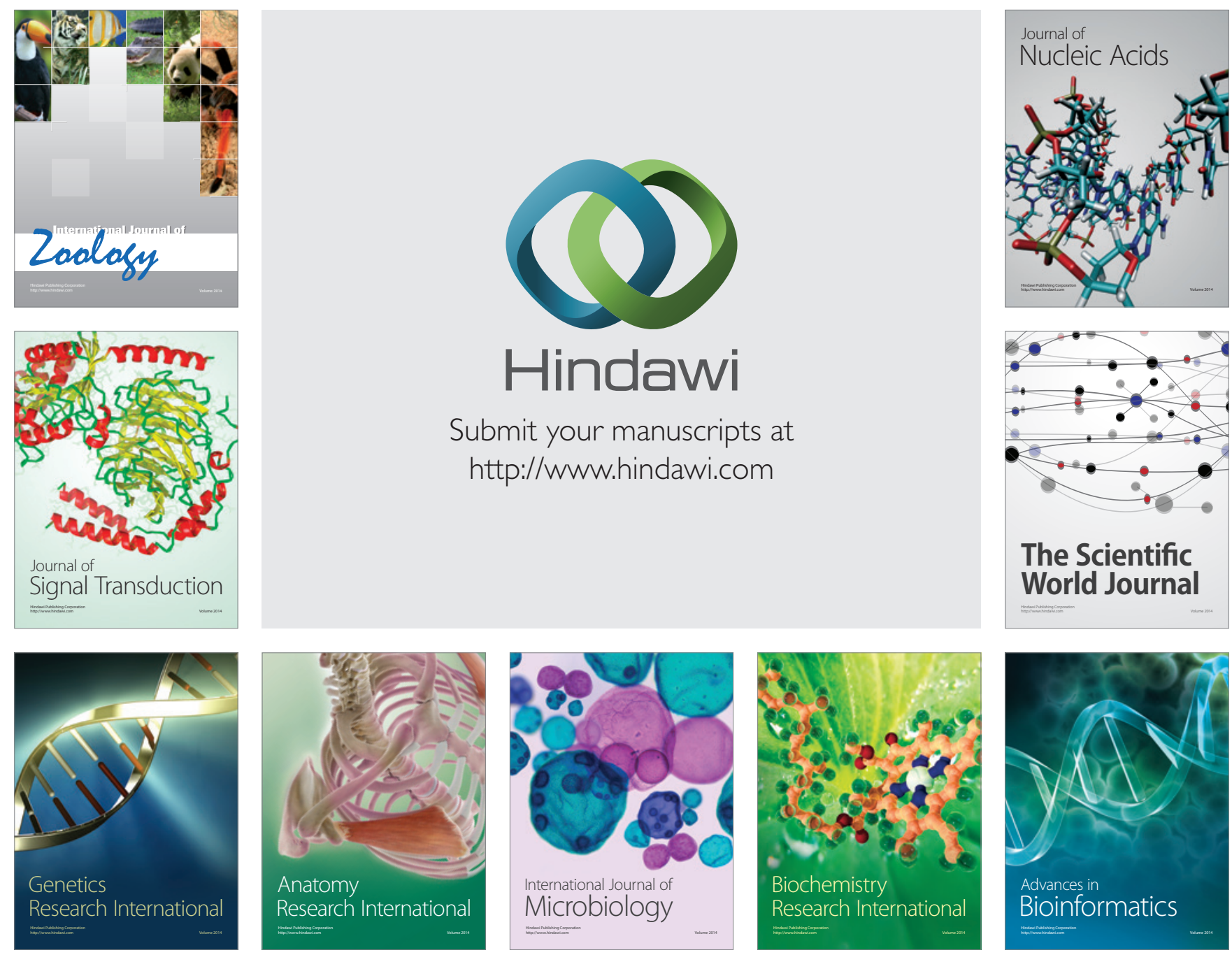

The Scientific World Journal
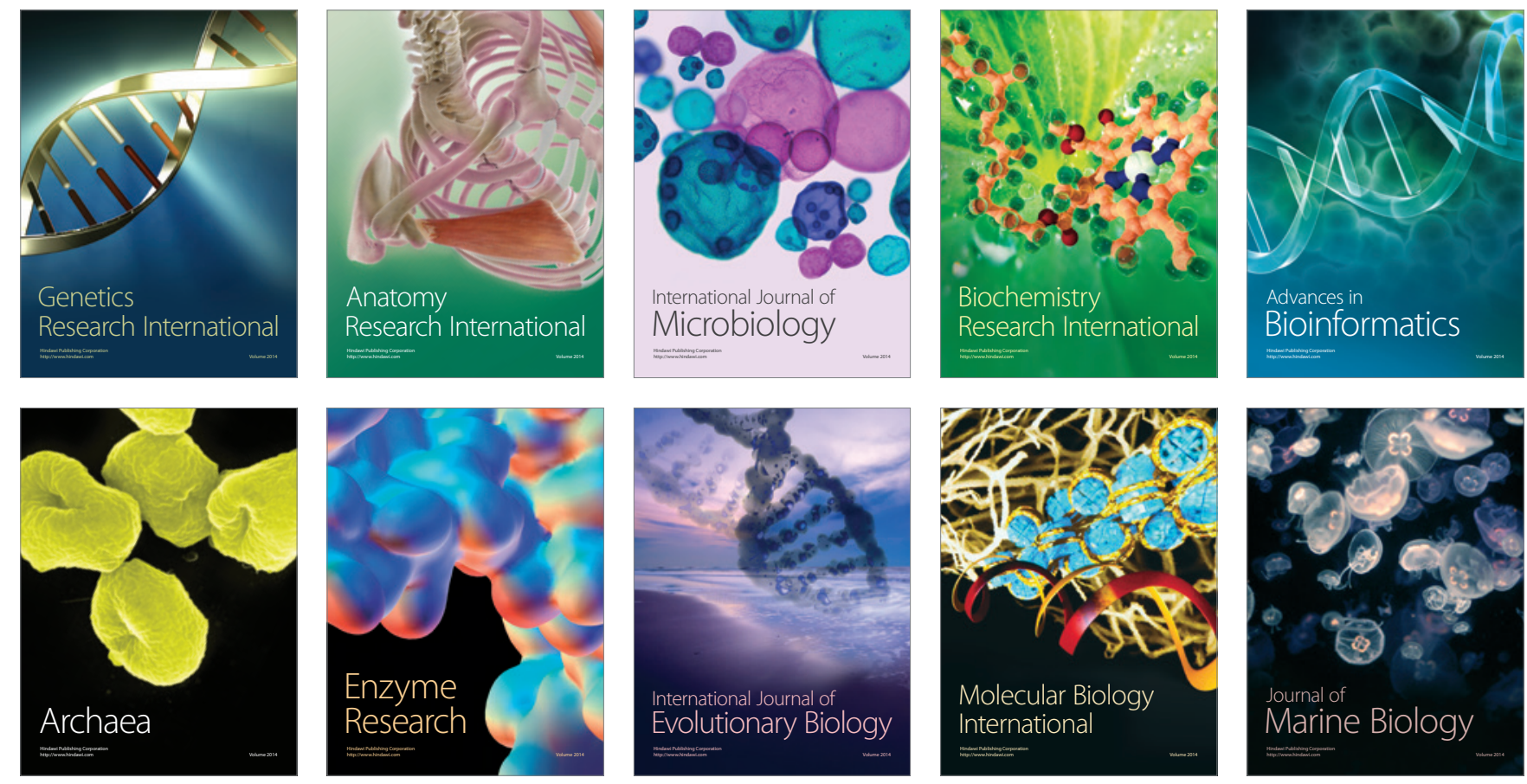